\title{
Corrosion-Induced Gas Generation in a Nuclear Waste Repository: Reactive Geochemistry and Multiphase Flow Effects
}

\author{
Tianfu $\mathrm{Xu}^{1}$, Rainer Senger ${ }^{2}$, and Stefan Finsterle ${ }^{1}$ \\ ${ }^{1}$ Earth Sciences Division, Lawrence Berkeley National Laboratory, Berkeley, CA 94720, \\ USA \\ ${ }^{2}$ INTERA Inc., 1812 Centre Creek Drive, Suite 300, Austin, Texas 78754, USA
}

\begin{abstract}
Corrosion of steel canisters, stored in a repository for spent fuel and high-level nuclear wastes, leads to the generation and accumulation of hydrogen gas in the backfilled emplacement tunnels, which may significantly affect long-term repository safety. Previous studies used $\mathrm{H}_{2}$ generation rates based on the volume of the waste or canister material and the stochiometry of the corrosion reaction. However, iron corrosion and $\mathrm{H}_{2}$ generation rates vary with time, depending on factors such as amount of iron, water availability, water contact area, and aqueous and solid chemistry. To account for these factors and feedback mechanisms, we developed a chemistry model related to iron corrosion, coupled with two-phase (liquid and gas) flow phenomena that are driven by gas-pressure buildup associated with $\mathrm{H}_{2}$ generation and water consumption. Results indicate that by dynamically calculating $\mathrm{H}_{2}$ generation rates based on a simple model of corrosion chemistry, and by coupling this corrosion reaction with two-phase flow processes, the degree and extent of gas pressure buildup could be much smaller compared to a model that neglects the coupling between flow and reactive transport mechanisms. By considering the feedback of corrosion chemistry, the gas pressure increases initially at the canister, but later decreases and eventually returns to a stabilized pressure that is slightly higher than the background pressure. The current study focuses on corrosion under anaerobic conditions for which the coupled hydrogeochemical model was used to examine the role of selected physical parameters on the $\mathrm{H}_{2}$ gas generation and corresponding pressure buildup in a nuclear waste repository. The developed model can be applied to evaluate the effect of water and mineral chemistry of the buffer and host rock on the corrosion reaction for future site-specific studies.
\end{abstract}

Key words. Nuclear waste repository, Canister corrosion, Hydrogen gas generation, Reactive geochemistry, Two-phase flow. 


\section{Introduction}

After closure of an underground nuclear waste repository, anaerobic conditions will be reached rapidly in the repository (within a few hundred years) and gases mainly $\mathrm{H}_{2}$ will form by anoxic corrosion of steel canister (Galle, 2000; Ortiz et al., 2002). Corrosion of iron and degradation of waste canisters leads to the generation and accumulation of hydrogen gas in the backfilled emplacement tunnels, which may significantly affect long-term repository safety.

Many investigators have performed experimental and modeling studies on steel canister corrosion and $\mathrm{H}_{2}$ generation and migration. Galle (2000) reported controlled $\mathrm{H}_{2}$ gas migration experiments with Fo-Ca clay, possible candidate for the disposal clayengineered barrier in France. Their results suggest that gas issue cannot be underestimated for the long-term engineered clay barrier stability. Ortiz et al. (2002) presented a conceptual model describing the interaction between the generated gas and the geosphere for Boom Clay, a proposed host formation for nuclear waste storage in Belgium. Their numerical simulations indicate that a hydrogen phase generated by the anaerobic corrosion could be formed and its pressure could exceed the local total stress, leading to a mechanical deformation of the rock and to the formation of a preferential pathway for the migration of gas and possibly contaminated water. de Combarieu et al. (2007) presented studies on iron corrosion in Callovo-Oxfordian argillite, France. Batch experiments for the corrosion of pure iron in the raw argillite were carried out at $90{ }^{\circ} \mathrm{C}$ for a maximum of six months, under oxygen-free atmosphere. XRD measurements determined that the main phase formed from the iron corrosion is magnetite. In the field of remediation of groundwater contamination by halogenated hydrocarbons, permeable iron reactive barriers are commonly used, iron corrosion and $\mathrm{H}_{2}$ gas generation have been also studied (Reardon, 2005).

In this paper, we examine specific corrosion reactions and their dependence on hydrogeochemical and two-phase flow conditions at the canister and in the surrounding (man-made and geologic) materials. Site-specific and detailed information will be required to assess the coupled processes and their impact at any particular site, and to 
develop engineering designs. Before moving into site-specific investigations, general features and issues representing characteristics that are common and essential for many such systems are explored. The present study is not related to any particular site. However, the geometric configuration and the hydraulic parameters of the clayey formation are abstracted from a nuclear waste repository concept considered in Switzerland (NAGRA, 2002). The reference design for canisters to be stored in a repository for spent fuel and high-level waste (SF/HLW) involves a cast steel body with about $20 \mathrm{~cm}$ wall thickness. The canisters are about $1 \mathrm{~m}$ in diameter and are surrounded by a $0.75-\mathrm{m}$ thick bentonite buffer in emplacement tunnels which are $2.5 \mathrm{~m}$ in diameter (Fig. 1). The repository tunnel is assumed to be in the water-saturated zone at a depth of $650 \mathrm{~m}$ below the land surface; the host rock is referred to as Opalinus clay.

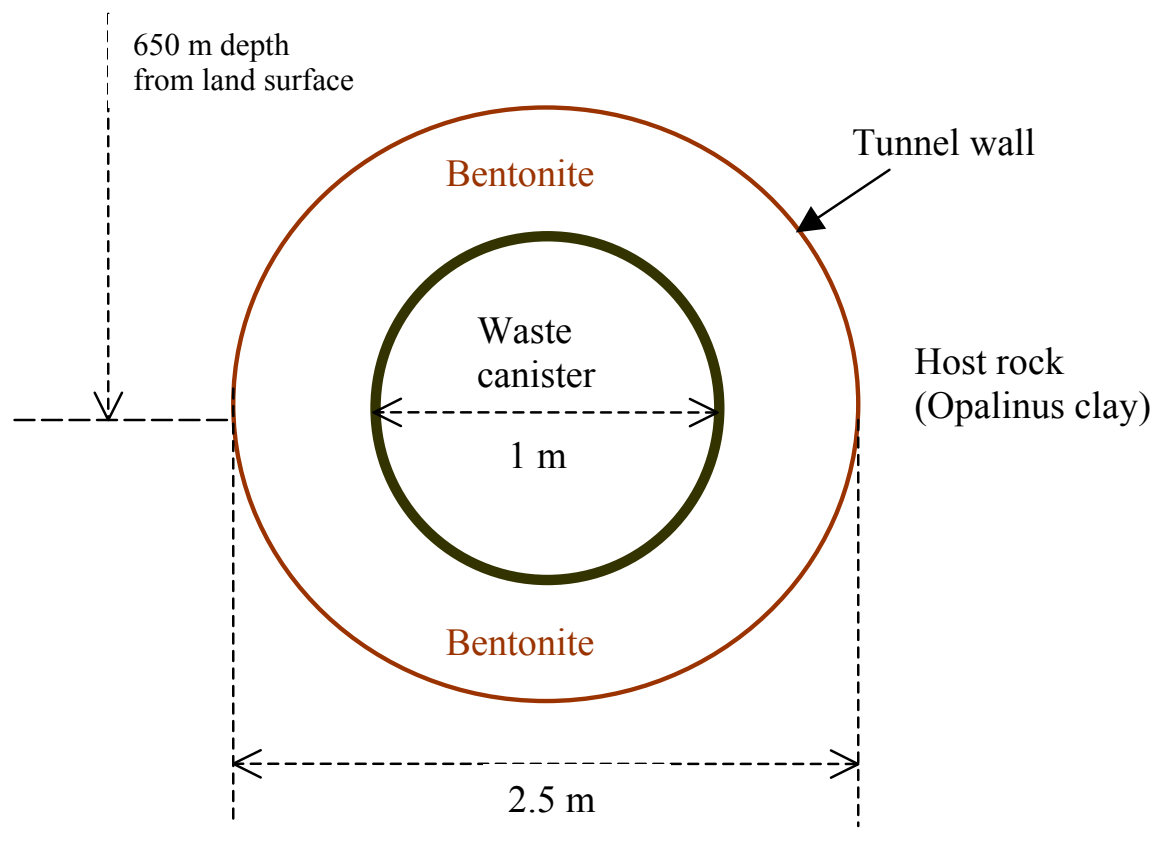

Fig. 1. Schematic representation of a nuclear waste repository with a single waste canister, bentonite backfill, and Opalinus clay host rock (NAGRA, 2002).

For the safety analysis, a series of simulations was performed to evaluate the sensitivity of assumed gas generation rates for different scenarios, as well as site-specific 
conditions (NAGRA, 2004). The simulation results indicate that gas pressures in the emplacement tunnels are unlikely to exceed the minimum stress, which is considered a threshold value for the onset of irreversible deformation of the intact host rock (NAGRA, 2004). A detailed assessment of two-phase flow in a SF/HLW repository was conducted by Senger et al. (2007), who examined different phenomena of hydrogen gas migration and water consumption associated with the corrosion of a waste canister, including the transport of gas, water, and vapor.

These previous studies were carried out using a constant $\mathrm{H}_{2}$ generation rate. However, iron corrosion and $\mathrm{H}_{2}$ generation rates potentially vary with time, depending on factors such as the amount of iron, water availability, water contact area, and water chemistry. To accurately account for these factors and feedback mechanisms, we developed a chemistry model related to iron corrosion and $\mathrm{H}_{2}$ generation, coupled with two-phase (liquid and gas) flow phenomena that are driven by gas-pressure buildup and water consumption. Uncoupled batch geochemical modeling and flow simulation as carried out previously are inadequate to describe the complex physical and chemical interactions expected to occur. The purpose of this work is to develop and apply a coupled reactive chemical and two-phase flow model to evaluate the impact of corrosion reaction on $\mathrm{H}_{2}$ generation and associated gas migration on the system state in a nuclear waste repository. A number of simplifications and assumptions are made in the present modeling analysis (see Section 2.4). This paper is not intended to fully evaluate mechanical and chemical impacts on the bentonite buffer and on the Opalinus clay host rock. Instead, it investigates select physical parameters that affect $\mathrm{H}_{2}$ gas generation and its impacts on a generic repository system. The study focuses on the long-term postclosure conditions after the repository is fully water saturated, characterized by anaerobic conditions. Furthermore, temperature effects associated with heat generation from radioactive decay, which are assumed to dissipate within a few hundred years after repository closure, are not considered. 


\section{Process Model}

\subsection{Chemical Reactions}

It is generally accepted that the largest gas generation source will be the anaerobic corrosion of the iron contained in the steel canister (Neretnieks, 1985; Ortiz et al., 2002). The following chemical reactions are involved in anaerobic corrosion (Reardon, 1995; Ortiz et al., 2002):

$$
\mathrm{Fe}+2 \mathrm{H}_{2} \mathrm{O} \leftrightarrow \mathrm{Fe}^{2+}+2 \mathrm{OH}^{-}+\mathrm{H}_{2}
$$

Part of $\mathrm{OH}^{-}$generated in Reaction (1a) may be involved in dissolving the bentonite or precipitating carbonates or hydroxides (more discussion is given in Section 2.4). The other part of $\mathrm{OH}^{-}$involves in reaction (1b),

$$
\mathrm{Fe}^{2+}+2 \mathrm{OH}^{-} \leftrightarrow \mathrm{Fe}(\mathrm{OH})_{2}
$$

The ferrous hydroxide $\left(\mathrm{Fe}(\mathrm{OH})_{2}\right)$ is metastable in anaerobic groundwater environments (Reardon, 1995) and converts thermodynamically to magnetite $\left(\mathrm{Fe}_{3} \mathrm{O}_{4}\right)$ according to the Shikorr reaction:

$$
3 \mathrm{Fe}(\mathrm{OH})_{2} \leftrightarrow \mathrm{Fe}_{3} \mathrm{O}_{4}+2 \mathrm{H}_{2} \mathrm{O}+\mathrm{H}_{2}
$$

By combining Reactions (1a), (1b), and (2), the overall iron corrosion reaction can be expressed as:

$$
3 \mathrm{Fe}+4 \mathrm{H}_{2} \mathrm{O} \leftrightarrow \mathrm{Fe}_{3} \mathrm{O}_{4}+4 \mathrm{H}_{2}
$$

Laboratory experiments on corrosion of iron metal under atmospheric conditions indicate that the corrosion rate decreases drastically if relative humidity decreases from $90 \%$ to $60 \%$ (Brown and Masters, 1982). Thermodynamic considerations predict that the gas production stops when the $\mathrm{H}_{2}$ partial pressure increases above $40 \mathrm{MPa}$ (Neretnieks, 1985). Even though pressure buildup is expected to be less than the $40 \mathrm{MPa}$ and relative 
humidity is likely to remain above $90 \%$, the corrosion rate is likely affected by water availability, water contact area, and water and material chemistry.

Table 1 summarizes chemical reactions among aqueous, gaseous and mineral phases considered in our present study. Thermodynamic data for these reactions were taken from the EQ3/6 V7.2b database (Wolery, 1992). Aqueous-aqueous and aqueousgaseous reactions are assumed at local equilibrium. Iron dissolution (corrosion) and magnetite precipitation are considered under kinetic conditions. The kinetic rate expression is given in the next section.

Table 1. List of chemical reactions among aqueous, gaseous and mineral phases considered in the present simulations. In the chemical model, aqueous species at the right-hand side are considered as primary species; all other aqueous species, gases and minerals are secondary species.

\begin{tabular}{|l|}
\hline Aqueous reactions: \\
$\mathrm{OH}^{-}=\mathrm{H}_{2} \mathrm{O}+\mathrm{H}^{+}$ \\
$\mathrm{Fe}^{3+}=\mathrm{H}^{+}+\mathrm{Fe}^{2+}-0.5 \mathrm{H}_{2}(a q)$ \\
$\mathrm{Fe}(\mathrm{OH})_{2}(a q)=2 \mathrm{H}_{2} \mathrm{O}-2 \mathrm{H}^{+}+\mathrm{Fe}^{2+}$ \\
$\mathrm{Fe}(\mathrm{OH})_{2}^{+}=2 \mathrm{H}_{2} \mathrm{O}-\mathrm{H}^{+}+\mathrm{Fe}^{2+}-0.5 \mathrm{H}_{2}(a q)$ \\
$\mathrm{Fe}(\mathrm{OH})_{3}(a q)=3 \mathrm{H}_{2} \mathrm{O}-2 \mathrm{H}^{+}+\mathrm{Fe}^{2+}-0.5 \mathrm{H}_{2}(a q)$ \\
$\mathrm{Fe}(\mathrm{OH})_{3}^{-}=3 \mathrm{H}_{2} \mathrm{O}-3 \mathrm{H}^{+}+\mathrm{Fe}^{2+}$ \\
$\mathrm{Fe}(\mathrm{OH})_{4}^{-}=4 \mathrm{H}_{2} \mathrm{O}-3 \mathrm{H}^{+}+\mathrm{Fe}^{2+}-0.5 \mathrm{H}_{2}(a q)$ \\
$\mathrm{O} 2(a q)=2 \mathrm{H}_{2} \mathrm{O}-2 \mathrm{H}_{2}(a q)$ \\
\hline $\mathrm{Gaseous}$ reactions: \\
$\mathrm{H}_{2}(\mathrm{~g})=\mathrm{H}_{2}(a q)$ \\
$\mathrm{O}_{2}(\mathrm{~g})=\mathrm{O}_{2}(a q)$ \\
\hline Mineral reactions: \\
iron $(\mathrm{Fe})=\mathrm{Fe}^{2+}+\mathrm{H}_{2}(a q)-2 \mathrm{H}^{+}$ \\
magnetite $\left(\mathrm{Fe}_{3} \mathrm{O}_{4}\right)=3 \mathrm{Fe}^{2+}+4 \mathrm{H}_{2} \mathrm{O}-6 \mathrm{H}^{+}-\mathrm{H}_{2}(a q)$
\end{tabular}




\subsection{Kinetic Rate Expression}

Similar to dissolution and precipitation of common mineral phases in geochemical modeling (Xu et al., 2006), we employed a transition state rate law (Lasaga et al., 1994) for iron dissolution and magnetite precipitation:

$$
r=k A\left[1-\left(\frac{Q}{K}\right)\right] .
$$

Here, $r$ is the kinetic rate (positive values indicate dissolution and negative values precipitation), $k$ is the rate constant (moles per unit mineral surface area and unit time), $A$ is the total reactive surface area for the grid block representing a steel canister, $K$ is the equilibrium constant for the mineral-water reaction written for the destruction of one mole of mineral, and $Q$ is the reaction quotient. For iron dissolution (corrosion), the rate can be expressed as (according to the iron reaction equation written in Table 1):

$$
r_{\text {iron }}=k A\left[1-\left(\frac{\left[F e^{2+}\right]\left[H_{2}(a q)\right]}{\left[H^{+}\right]^{2} K}\right)\right] .
$$

The surface area can be calculated from

$$
A=A_{0} \frac{V}{V_{0}} f\left(S_{w}\right)
$$

where $A_{0}$ is the initial surface area, and $V_{0}$ and $V$ are mineral (iron) volume fractions at initial and current times, respectively. The factor $f$, ranging from 0 to 1 , accounts for the area contacted by water divided by the total surface area. Here, we assume that $f$ depends on the water saturation $\left(S_{w}\right)$. At fully water-saturated conditions, $f=1$. At partially watersaturated conditions, the surface area of the mineral contacted by water is smaller than 
the total surface area, or $f<1$. The following relation of $f$ depending on $S_{w}$ is used in the present model:

$$
f\left(S_{w}\right)=\left(S_{w}\right)^{n}
$$

In Eq. (7), $\mathrm{n}$ is a parameter controlling the dependence of $f$ on $S_{w}$. We used $\mathrm{n}$ values ranging from zero to two in the simulations (see Section 4.4). By substituting Eqs. (6) and (7) into Eq. (5), the overall rate can be obtained from

$$
r_{\text {iron }}=k \cdot\left[A_{0} \frac{V}{V_{0}} S_{w}^{n}\right] \cdot\left[1-\left(\frac{\left[F e^{2+}\right]\left[H_{2}(a q)\right]}{\left[H^{+}\right]^{2} K}\right)\right] .
$$

The initial total surface area can be calculated from

$$
A_{0}\left(m^{2}\right)=V_{E}\left(m^{3}\right) \cdot(1-\phi) \cdot f_{v} \cdot \rho\left(g / m^{3}\right) \cdot A_{s}\left(m^{2} / g\right),
$$

where $V_{E}$ is the volume of the grid block containing the steel canister, $\phi$ is the porosity, $f_{v}$ is the initial volume fraction of iron in the solid phase, $\rho$ is the density of the steel canister, and $A_{s}$ is specific surface per unit iron mass (Section 4.3).

\subsection{Two-Phase Flow}

Gas generated due to the corrosion of the steel canister leads to a number of twophase flow phenomena. Initially, $\mathrm{H}_{2}$ gas is dissolved in the water present in the canister and in the surrounding buffer and host rock. As pore water becomes fully gas saturated and no more gas can be dissolved, the increase in gas partial pressure causes a free gas phase to form. Driven by the pressure buildup, gas starts to migrate into the surrounding, initially fully water-saturated bentonite buffer and further into the Opalinus clay host rock. There is a potential for some displacement of pore water as the gas front migrates from the canister through the buffer into the surrounding clay host rock. 
Corrosion continues as long as sufficient water is available for the redox reaction. The processes associated with the corrosion of the steel canister are focused on the surface of the canister that is in contact with the surrounding bentonite buffer, which is assumed to be initially fully water saturated. The water involved in the corrosion reaction is initially taken from the water in the waste canister or adjacent bentonite, and later by water and vapor transport toward the canister. Note that $\mathrm{H}_{2} \mathrm{O}$ consumed by Reaction (2) can be either water or vapor. The pressure buildup from gas generation produces a gas pressure gradient and gas flow away from the canister. This process is controlled by the hydraulic properties of the bentonite and Opalinus clay. Depending on the gas-pressure distribution and capillary pressure-saturation relationship of the canister, surrounding bentonite, and Opalinus clay, a liquid pressure gradient develops, allowing liquid water to flow toward the canister. Water vapor (generated by evaporation of liquid according to the equilibrium conditions at the given gas pressure and temperature) can be transported by diffusion toward the canister. This is because vapor is in equilibrium with the liquid phase as defined by the gas phase pressure: at higher $\mathrm{H}_{2}$ pressure the vapor concentration is smaller, leading to a vapor concentration gradient toward the canister, where the pressure is greatest. However, the gas pressure buildup from $\mathrm{H}_{2}$ generation results in advection of gas ( $\mathrm{H}_{2}$ and vapor) away from the canister, which produces a net flow of vapor away from the canister. At later times, after the $\mathrm{H}_{2}$ gas front extends into the buffer and surrounding Opalinus clay, water consumed by the corrosion reaction is provided largely by water flow toward the waste canister.

\subsection{Assumptions and Limitations}

A number of simplifying assumptions have been made in this preliminary analysis. We did not attempt to develop a detailed mechanistic corrosion model rather than considered a simple bulk chemistry model from the $\mathrm{H}_{2}$ mass balance point of view. The current corrosion model only considers iron oxidation by water, which can occur (the hydrolysis of water) but under reducing conditions. We also did not account for $\mathrm{H}_{2}$ production by the radiolysis of water (Lapuerta et al., 2007). In addition, the produced $\mathrm{H}_{2}$ could become a donor for other redox reactions and thus would be in part consumed. Experimental results of Ortiz et al. (2002) indicate that the presence of methane-forming 
bacteria in Boom Clay (Belgium) can reduce the $\mathrm{H}_{2}$ gas source term, as the bacteria use four molecules of hydrogen in their metabolic reactions to form one molecule of methane $\left(\mathrm{CH}_{4}\right)$. Excluding the microbial reactions likely underestimates the total gas pressure and its mechanical consequences. According to these investigators, sulfate-reducing bacteria were found in Boom Clay, but no release of hydrogen sulfide has ever been established during gas generation experiments performed in batch reactors. By calculating the corrosion rate constants based on the experimental $\mathrm{H}_{2}$ production rates as discussed in Section 2.2, we probably limit the estimation errors of $\mathrm{H}_{2}$ production.

Releases of chemical constituents from surrounding waste materials, bentonite buffer, and host Opalinus clay can potentially influence iron corrosion and gas generation. For example, silicon released from waste glass can adsorb on the surface of magnetite and other corrosion products of iron (Philippini et al., 2006). In addition, bentonite dissolution can be enhanced at high $\mathrm{pH}$ (Bauer and Berger, 1998). The consumption of $\mathrm{OH}^{-}$enhances the progress of Reaction (1a), and then may modify the amount of magnetite predicted by Reaction (3). During the simulation time, changes in water chemistry are dynamically calculated from the coupled model. Data on porewater chemistry and mineralogy of the Opalinus Clay are available in Pearson et al. (2003), Fernández et al. (2006), and Gaucher et al. (2006). These data could be the starting point of a more elaborate chemical modeling of the interaction between the canister and the clayey materials. In the current study, an initial dilute water was assumed.

Heat generation from the waste package was not considered in the current model. A constant temperature of $40{ }^{\circ} \mathrm{C}$ was used throughout the model domain and simulation time, representative of long-term post-closure conditions when the repository is fully water saturated and anaerobic conditions prevail. The early-time elevated temperatures are assumed to dissipate within a few hundred years. The potential corrosion under oxidizing conditions (Davydov et al., 2005) at early time was not considered in the current study (when the repository is partially saturated and the waste containers are at relatively high temperatures). Compared to the longer-term anaerobic corrosion, the early-time aerobic corrosion may be not significant.

\section{Numerical Implementation}


The previous modeling of processes associated with a constant $\mathrm{H}_{2}$ gas generation due to corrosion of the waste canister and the potential impact of $\mathrm{H}_{2} \mathrm{O}$ consumption is implemented in iTOUGH2 (Finsterle, 1999; 2004), which is an inverse code coupled to the nonisothermal two-phase fluid and heat flow code TOUGH2 (Pruess, 1991).

TOUGH2 considers different fluid mixtures (i.e., water and air; water and hydrogen), which are given in different fluid property modules (also referred to as "equation-of-state" or "EOS" modules). TOUGH2 simulates flow in both liquid and gaseous phases occurring under pressure, viscous, and gravity forces according to Darcy's law. Interference between the phases is represented by means of relative permeability and capillary pressure functions. The code includes Klinkenberg effects and binary diffusion in the gas phase, and capillary and phase adsorption effects for the liquid phase. Thermophysical properties of water (i.e., density and viscosities) are represented by steam table equations provided by the International Formulation Committee (1967). The basic equations and numerical implementation are described in detail in Pruess (1991).

In a first approximation, the water consumption associated with corrosion is represented by an equivalent water withdrawal rate, which is prescribed together with the corresponding gas generation rate to the grid blocks representing the canister hull. The detailed physico-chemical processes at the interface between the canister surface and the surrounding bentonite are approximated in the numerical model by prescribing the reaction products in terms of constant gas-generation and water-consumption rates over time.

In the present work, $\mathrm{H}_{2}$ gas generation rates and corresponding $\mathrm{H}_{2} \mathrm{O}$ consumption rates due to iron corrosion are dynamically calculated from the chemistry model presented above. The reactive geochemical transport part of TOUGHREACT (Xu and Pruess, 2001) was linked to iTOUGH2. TOUGHREACT is a nonisothermal reactive geochemical transport program that was developed by introducing reactive geochemistry into TOUGH2. TOUGHREACT can deal with a wide range of subsurface coupled thermal-physical-chemical processes under various thermal-hydrological and geochemical conditions (Xu et al., 2006). It can accommodate any number of chemical species present in aqueous, gaseous, and solid phases. A variety of equilibrium chemical reactions are considered, such as aqueous complexation, gas dissolution and exsolution, 
and cation exchange. Mineral dissolution and precipitation can proceed either subject to local equilibrium or kinetic conditions. Chemical components can undergo linear adsorption and radioactive decay.

The modeling of flow and transport in geologic media is based on space discretization by means of integral finite differences (IFD; Narasimhan and Witherspoon, 1976). The IFD method provides for flexible discretization using irregular grids, which is well suited for simulation of flow, transport, and fluid-rock interaction in heterogeneous and fractured rock systems with varying petrology and complex model boundaries due to the presence of engineered structures. For regular grids, the IFD method is equivalent to the conventional finite difference method. An implicit time-weighting scheme is used for modeling flow, transport, and kinetic geochemical reactions. The TOUGH suite of codes can be applied to one-, two-, or three-dimensional porous single- or multiple-continuum media, with physical and chemical heterogeneity.

\section{Problem Setup}

\subsection{Model Geometry}

Given the radial geometry of the repository (Fig. 1), a simplified model previously used by Senger et al. (2007) was employed here for the coupled modeling. The model is represented by a radially-symmetric geometry, ignoring the lateral no flow boundary and gravity effects (Fig. 2). 


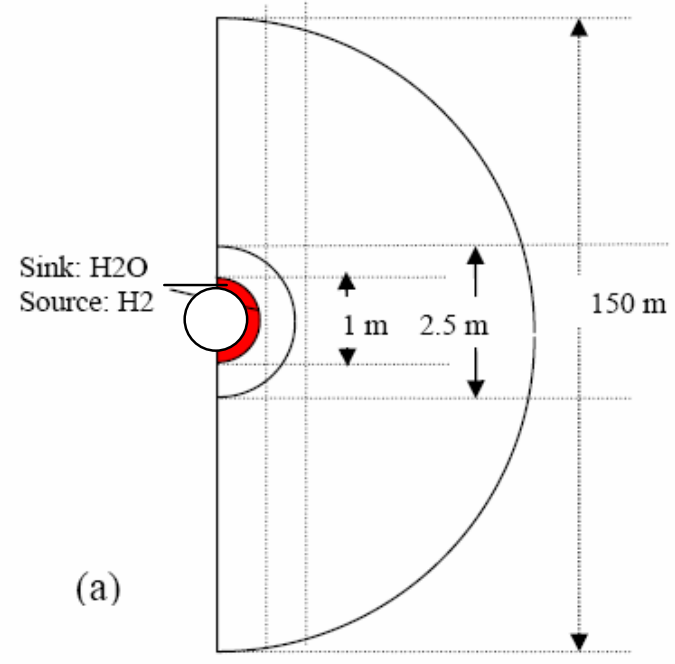

Fig. 2. Radially-symmetric model used in the current study, representing a single waste canister, canister hull, bentonite backfill, and the Opalinus clay host rock.

\subsection{Thermo-Physical Conditions and Parameters}

The repository is located $650 \mathrm{~m}$ below the land surface. For the current modeling, the system is assumed to be initially fully water-saturated with a background pressure of 65 bar. The outer boundary at a radial distance of $75 \mathrm{~m}$ was prescribed with a constant pressure of 65 bar. Heat generation from the waste package was not considered in the current model; a constant temperature of $40{ }^{\circ} \mathrm{C}$ was used throughout the model domain and simulation time, representative of late-time conditions. The thermo-physical properties for the different materials (waste canister, bentonite buffer, and Opalinus clay) are summarized in Table 2. A porosity of 0.1 was used for the grid block representing the container hull, which includes the portion of water at the interface between the canister and the buffer contacting the canister surface. The van Genuchten model (van Genuchten, 1980; Mualem, 1976) is used to describe the functional relationships between relative permeability and saturation, and capillary pressure and saturation for the different materials (Table 2). 
Table 2. Thermo-physical parameters used for the different materials modified from NAGRA (2004).

\begin{tabular}{|c|c|c|c|}
\hline & Waste Canister & Bentonite & Opalinus Clay \\
\hline Porosity [-] & 0.1 & 0.40 ("MX-80") & 0.12 \\
\hline Permeability $\left[\mathrm{m}^{2}\right]$ & $1 \times 10^{-19}$ & $1 \times 10^{-19}$ & $1 \times 10^{-20}$ \\
\hline Pore compressibility $(\alpha / \phi)\left[\mathrm{Pa}^{-1}\right]$ & $2.14 \times 10^{-9}$ & $3.58 \times 10^{-9}$ & $1.83 \times 10^{-9}$ \\
\hline Two-Phase Parameter Model ${ }^{1}$ & Van Genuchten & Van Genuchten & Van Genuchten \\
\hline Residual liquid saturation [-] & 0.0 & 0.3 & 0.5 \\
\hline Initial liquid saturation [-] & 1.0 & 1.0 & 1.0 \\
\hline Residual gas saturation [-] & 0.0 & 0.0 & 0.0 \\
\hline Van Genuchten parameter $n[-]$ & 2.0 & 1.82 & 1.67 \\
\hline Gas entry pressure $[\mathrm{Pa}]$ & 1.0 & $1.8 \times 10^{7}$ & $1.8 \times 10^{7}$ \\
\hline
\end{tabular}

${ }^{1}$ van Genuchten (1980), Mualem (1976).

\subsection{Chemical Conditions and Parameters}

An initial dilute water with very low ion concentrations was assumed. Constant aqueous concentrations (also dilute water) are specified at the outer boundary. Initially, a volume fraction of iron of 0.8 in terms of solid phase was assumed available for the corrosive reactions. By accounting for a porosity of 0.1 , the initial iron volume fraction in terms of medium is 0.72 , which is used in the simulation result presentation (Fig. 9).

NAGRA $(2002,2004)$ gave a range of $\mathrm{H}_{2}$ generation rates from a realistic rate of $0.0112 \mathrm{~m}^{3} / \mathrm{a}$ per tunnel meter $(\mathrm{tm})\left(2.938 \times 10^{-11} \mathrm{~kg} / \mathrm{s}\right)$ to a very conservative rate of 0.4 $\mathrm{m}^{3} / \mathrm{a} / \mathrm{tm}\left(1.049 \times 10^{-9} \mathrm{~kg} / \mathrm{s}\right)$, which correspond to $\mathrm{H}_{2} \mathrm{O}$ consumption rates of $2.644 \times 10^{-10}$ $\mathrm{kg} / \mathrm{s}$ and $9.441 \times 10^{-9} \mathrm{~kg} / \mathrm{s}$, respectively. This range depends on the variation in the loading of canisters and the geometry of the cavern and canister in the drift (NAGRA, 2004). The current study used two simulation cases based on the lower (pessimistic) $\mathrm{H}_{2}$ 
generation rate of $0.04 \mathrm{~m}^{3} / \mathrm{a} / \mathrm{tm}$ and the higher (very conservative) $\mathrm{H}_{2}$ generation rate of $0.4 \mathrm{~m}^{3} / \mathrm{a} / \mathrm{tm}$, and corresponding $\mathrm{H}_{2} \mathrm{O}$ consumption rates.

The chemical model requires input in terms of the corrosion or iron dissolution rate constant (k) according to Eq. (8). The iron dissolution rate can be calculated stoichometrically from the corresponding measured $\mathrm{H}_{2}$ generation rates, according to Reaction (2), or generated four moles of $\mathrm{H}_{2}$ consumes three moles of Fe. For a water solution far from equilibrium, the dissolution rate of Eq. (5) becomes $r_{\text {iron }}=k A$. By applying Eq. (9) and using a canister grid block volume of $0.2827 \mathrm{~m}^{3}$, a density of 7,874 $\mathrm{kg} / \mathrm{m}^{3}$ and a specific surface area of $121.8 \mathrm{~cm}^{2} / \mathrm{g}$, the two constant $\mathrm{H}_{2}$ generation rates of 0.04 and $0.4 \mathrm{~m}^{3} / \mathrm{a} / \mathrm{tm}$ correspond to iron dissolution rate constants $(\mathrm{k})$ of $2.0 \times 10^{-12}$ and $2.0 \times 10^{-11} \mathrm{~mol} / \mathrm{m}^{2} / \mathrm{s}$, respectively. Ortiz et al. (2002) reported an iron dissolution rate constant determined from experiment of $2.4 \times 10^{-12} \mathrm{~mol} / \mathrm{m}^{2} / \mathrm{s}$ for $316 \mathrm{~L}$ stainless steel contacting with pure water (they reported in terms of a $\mathrm{H}_{2}$ generation rate constant, in this paper we converted to iron dissolution rate constant and normalized using our specific surface area). The lower iron dissolution (corrosion) rate constant we used is very close to their experimental value. The actual corrosion rate may decrease over time mainly because of (1) reduction of iron volume, and (2) reduction of water contact areas, which is dynamically calculated according to Eq. (9).

\subsection{Simulations}

Two sets of simulations were performed for a time period of 5,000 years using the two iron dissolution rate constants of $2.0 \times 10^{-12}$ and $2.0 \times 10^{-11} \mathrm{~mol} / \mathrm{m}^{2} / \mathrm{s}$, derived above. In a series of simulations different controls on the corrosion rate are examined using different values of the exponent $n$ (Eq. 7), which affects the water contact area factor $f$ and then the effective surface area $A$ (Eq. 6). For the base-case simulation, the water contact area factor $f$ is assumed to be one by setting the exponent $n=0$ (Eq. 7), indicating that the iron dissolution rate does not depend on the water saturation, but only on the iron volume fraction (V), which directly affects the reactive surface area (Eq. 6). The sensitivity simulations assume that $f$ varies as a function of saturation using different values of the exponent $n$ (Eq. 7). For $n=1$ the fraction of water contact area $f$ equals the 
water saturation $S_{w}$; for $0<n<1, f$ is greater than $S_{w}$; for $n>1, f$ is less than $S_{w}$. In the present work, the following $\mathrm{n}$ values are used: $0,0.1,0.2,0.5,1$, and 2 .

\section{Results and Discussion}

The pressure distribution along the radial distance for two base-case simulations is presented in Fig. 3. For the lower rate case, the gas pressure buildup ( $p>65$ bar, the background pressure) extends to a radial distance of about $20 \mathrm{~m}$ after 5,000 years. For the higher rate case, the gas pressure buildup extends to a radial distance of about $50 \mathrm{~m}$.

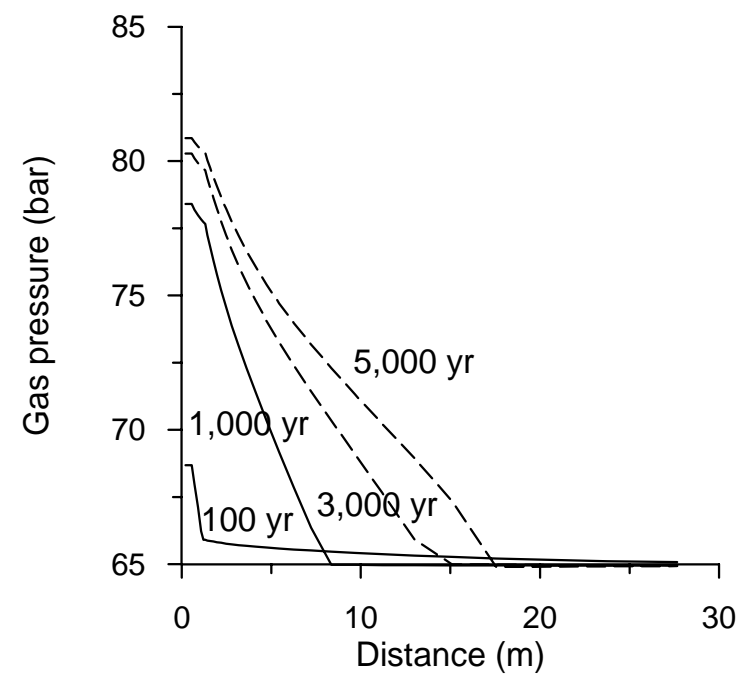

(a) Lower rate

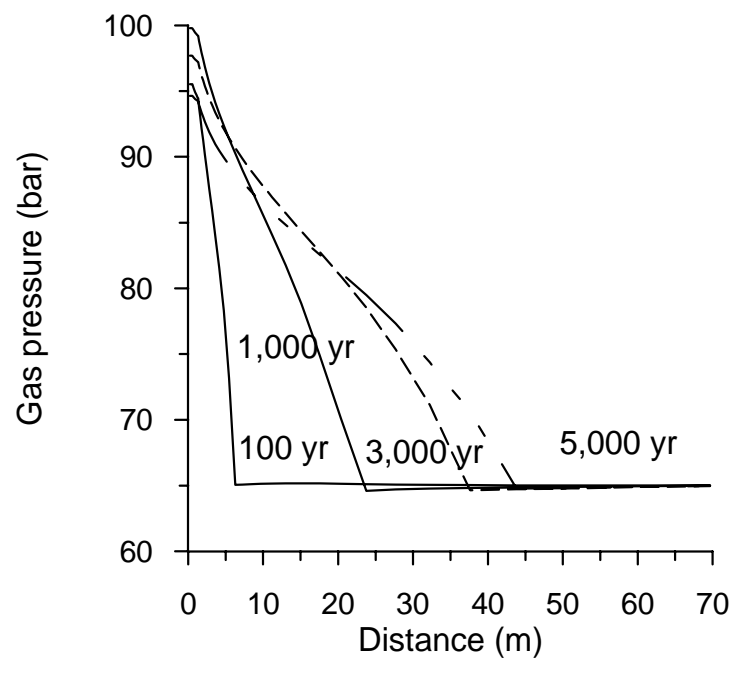

(b) Higher rate

Fig. 3. Distribution of gas pressure buildup over radial distance at different times for $n=$ 0 base-case simulations.

For the lower-rate corrosion, the pressure evolution at the canister grid block for the simulations with different values of the $n$ parameter is shown in Fig. 4a. Generally for $n$ values of $0,0.1$ and 0.2 , pressures continuously increase during the simulation time period of 5,000 years. In the base-case simulation using $n=0$ (i.e., $f=1$, which means the corrosion rate does not depend on the water saturation and only depends on iron volume fraction), the simulated pressure increases to about 81 bar after 5,000 years. 
The pressure evolution in the base-case simulation is similar to a simulation that only considers two-phase flow with a constant $\mathrm{H}_{2}$ generation rate and corresponding $\mathrm{H}_{2} \mathrm{O}$ consumption rate (i.e, no coupling with the chemistry model). This is because the decrease in the iron volume fraction is relatively small for this short time period compared to the initial iron volume resulting in a nearly constant $\mathrm{H}_{2}$-generation rate, as discussed further below.

For $n$ values of $0.5,1$ and 2, the corrosion rate and the corresponding $\mathrm{H}_{2}$ generation rate depend strongly on the water saturation. The simulated pressures increase initially to a peak value not more than 70 bars. At later time, however, gas pressures decrease because of the decrease in water saturation and then gas generation rate (Fig. 5a). A final stabilized pressure of 65.5 bar is reached, which is only slightly greater than the background pressure of 65 bar. The amount of gas generation is equal to that migrating to the bentonite buffer and surrounding host rock, and the amount of water consumption is equal to the supply of water from the surrounding bentonite and host rock.

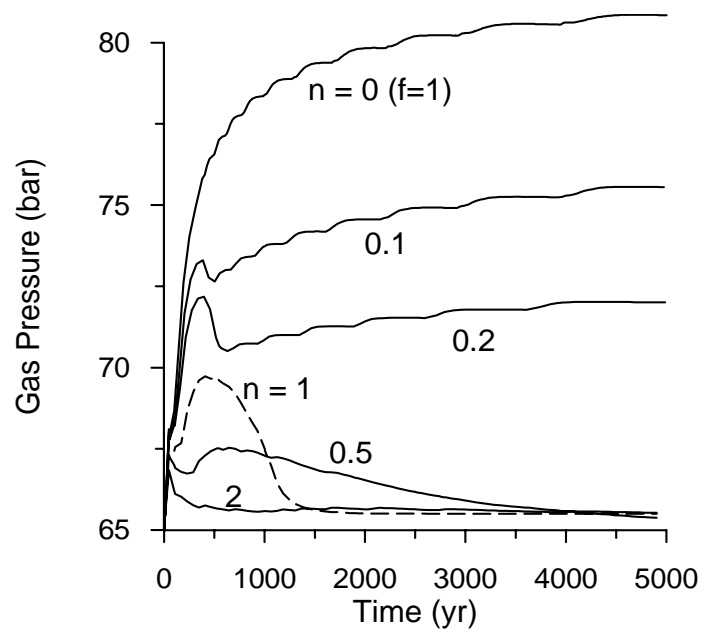

(a) Lower rate

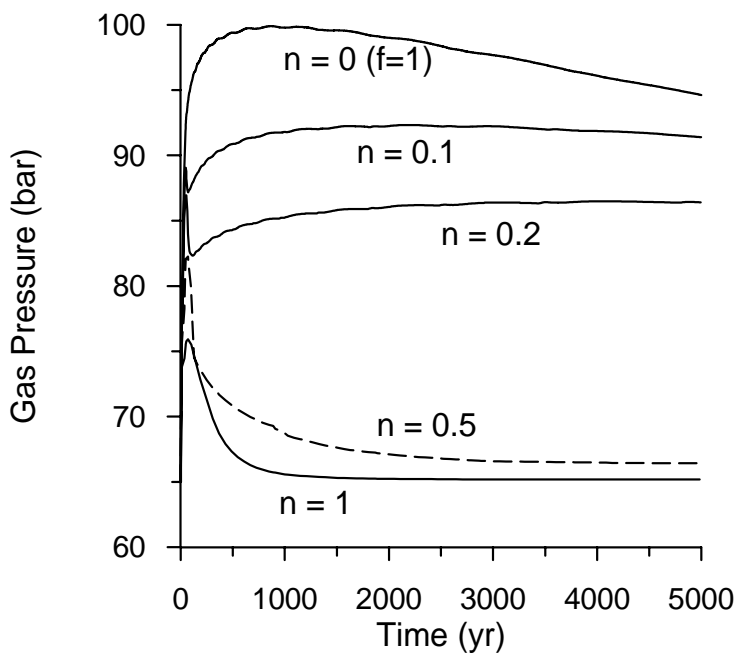

(b) Higher rate

Fig. 4. Pressure as a function of time at the canister surface obtained using a corrosion rate constant of (a) $2.0 \times 10^{-12} \mathrm{~mol} / \mathrm{m}^{2} / \mathrm{s}$ and (b) $2.0 \times 10^{-11} \mathrm{~mol} / \mathrm{m}^{2} / \mathrm{s}$ for different $n$ values relating water contact area to liquid saturation (note that $\mathrm{Y}$-axis of (b) is different from (a)). 
For the higher corrosion rate cases $\left(2.0 \times 10^{-11} \mathrm{~mol} / \mathrm{m}^{2} / \mathrm{s}\right)$, pressure evolution at the canister grid block for the simulations with different values of the $n$ parameter is shown in Fig. 4b. In the base-case simulation with $n=0$ (i.e., $f=1$ ), the gas pressure rapidly increases to about 100 bars after 100 years and then decreases gradually. For $n$ values of 0.1 and 0.2 , where the corrosion rate depends slightly on the water saturation, pressures increase steadily but do not reach 100 bars. For $n$ values above 0.5 , where the corrosion rate depends strongly on the water saturation, pressures increase at the very early time, but later decrease to a final stabilized pressure of $65.5 \mathrm{bar}$, similar to the lower rate cases.

The computed $\mathrm{H}_{2}$ generation rates and gas saturations at the waste container over time for all cases are presented in Figs. 5 and 6, respectively. For the base-case (i.e., $n=$ 0 and then $f=1$ ) the corrosion rate does not depend on the water saturation. At the lower corrosion case (Fig. 5a), the computed $\mathrm{H}_{2}$ generation rate increases initially, but later decreases slightly due to the reduction of iron volume and then the reduction of reactive surface area. For $n$ values greater than zero, the $\mathrm{H}_{2}$ generation rate shows the same initial increase as the base-case, because of the initial pore water available for the full corrosion, but decreases rapidly (Fig. 5a). For $n$ values of 0.1 and 0.2 , this initial decrease is followed by a near constant rate after 500 years. For $n$ greater than one (i.e., $f<\mathrm{S}_{\mathrm{w}}$ ), the overall $\mathrm{H}_{2}$ generation rate decreases continuously, because $\mathrm{f}<\mathrm{S}_{\mathrm{w}}$ and the corrosion rate decreases more because of the decrease in the surface area (Eq. 6).

For higher rate cases, an $n$ value of zero yields an overall rate increase at early time (Fig. 5b), which later decreases significantly due to significant reduction of the iron volume (Fig. 7b) and then corresponding decrease in the surface area (i.e., Eq. 6 showing that the reactive surface areas is proportional to the volume). For other $n$ values, the time evolution patterns are similar to the lower rate cases, but the early declines are much faster. For $\mathrm{n}=0.1$ and 0.2 , the $\mathrm{H}_{2}$ generation rates show a more gradual decline at late time (Fig. 5b). For $\mathrm{n}>0.5$, the $\mathrm{H}_{2}$ generation rates decline more rapidly due to the lower water saturations compared to the low-rate cases. The $\mathrm{H}_{2}$ gas saturations over time for all cases are presented in Fig. 6. The higher overall $\mathrm{H}_{2}$ generation rates, the faster near gassaturated conditions are reached. Note that the gas saturation could reach close to $100 \%$ but never reaches exactly $100 \%$, and in these cases a very small water saturation (in the order of 0.001 ) is obtained and a steady water flow into the grid block maintains the 
corrosion going. High gas saturations near $100 \%$ are reached only in the canister grid blocks, while adjacent bentonite grid blocks are still close to $100 \%$ liquid saturated. The mobility of each phase (liquid and gas) is controlled by upstream grid blocks. Gas flows from the upstream steel canister to the bentonite, but liquid flows from the bentonite to the steel canister. Phase permeabilities vary with saturation according to the van Genuchten (1980) curves with parameters given in Table 2.

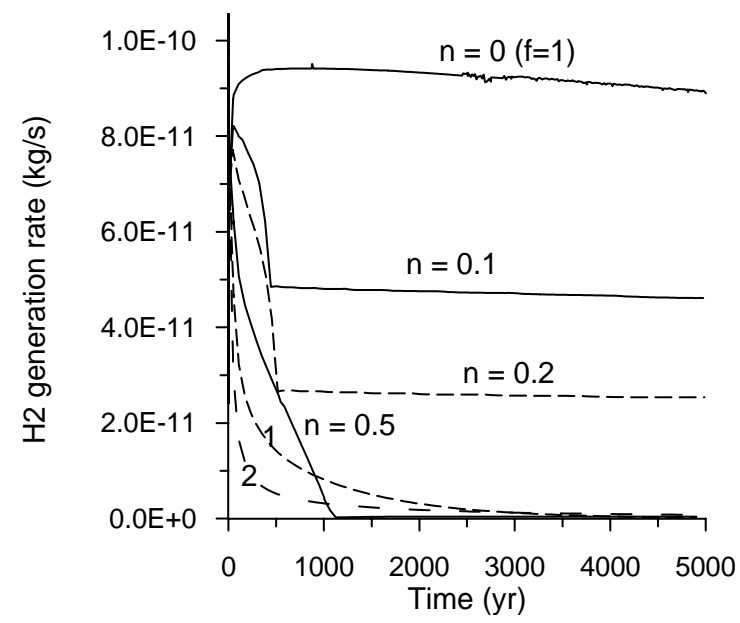

(a) Lower rate

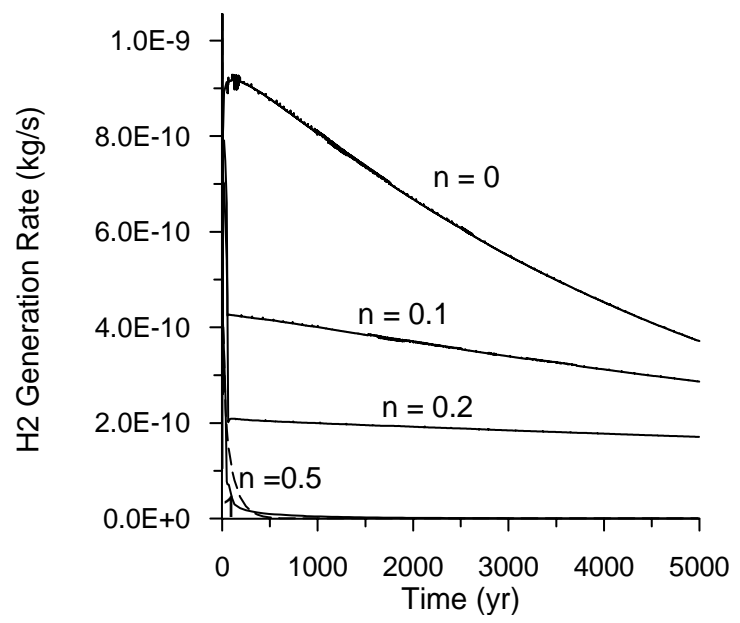

(b) Higher rate

Fig. 5. $\mathrm{H}_{2}$ generation rate as a function of time at the canister surface for different $n$ values relating water contact area to water saturation. 


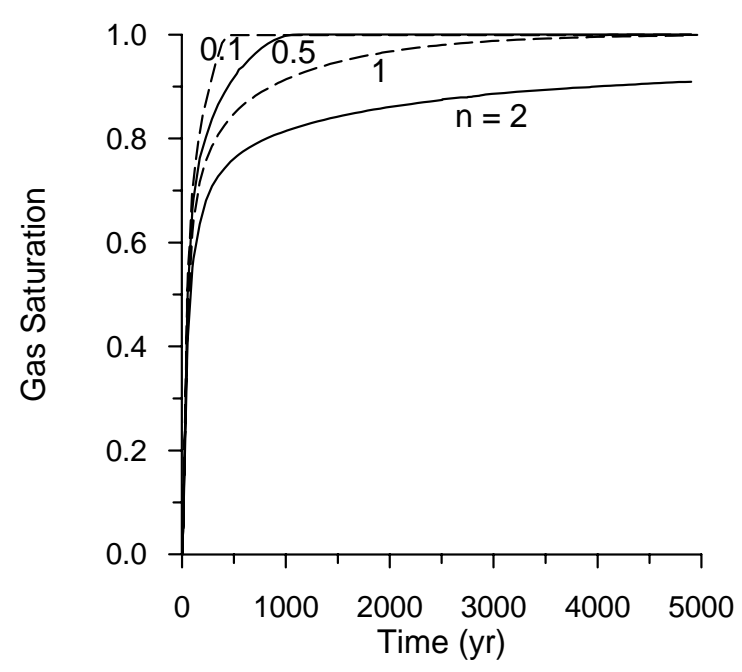

(a) Lower rate constant

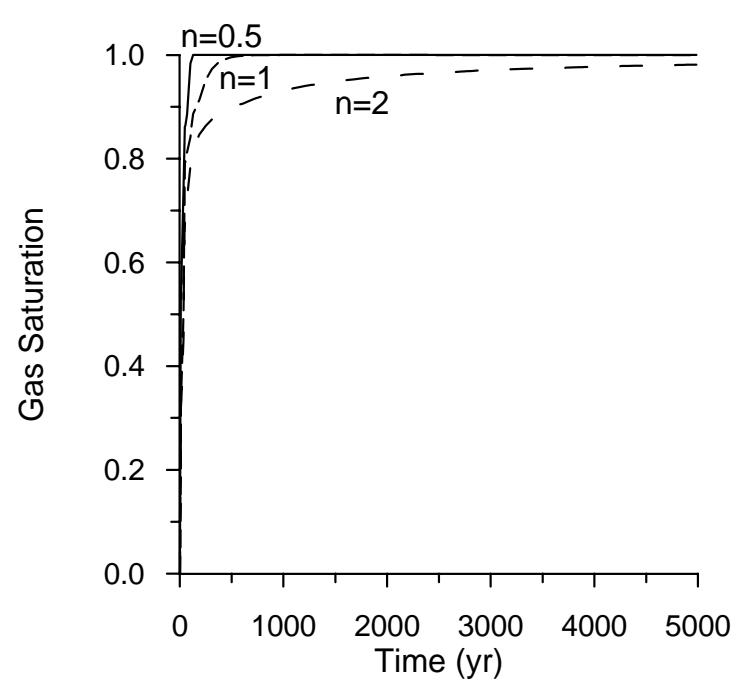

(b) Higher rate constant

Fig. 6. Gas phase saturation as a function of time at the canister for different $n$ values.

The amount of iron dissolution and magnetite precipitation is presented in Figs. 7 and 8 , respectively. The simulated conversion of iron (steel) to magnetite results in an overall volume increase by a factor of 2.1 which is consistent with values reported by Johnson and King (2003). Changes in porosity due to the iron corrosion and their effects on flow were not considered in the current problem, but the option is available in the simulator. As mentioned above, in the base-case simulation $(n=0)$ using the higher rate, the iron volume fraction is reduced by about $60 \%$ after 5,000 years (the initial iron volume fraction is 0.72 in terms of medium). The lower-rate base-case simulation obtained an iron volume reduction by only about $7 \%$. As a result, the obtained $\mathrm{H}_{2}$ generation for the base-case simulation only shows a relatively small gradual decline (Fig. 5a). In comparison, the high-rate base-case simulation having a significant ironvolume reduction shows a steeper decline in the $\mathrm{H}_{2}$ generation rate (Fig. 5b). If the corrosion rate is dependent on water saturation (i.e., $\mathrm{n}>0$ ), the amount of iron dissolved and concomitant $\mathrm{H}_{2}$ generation is reduced. 


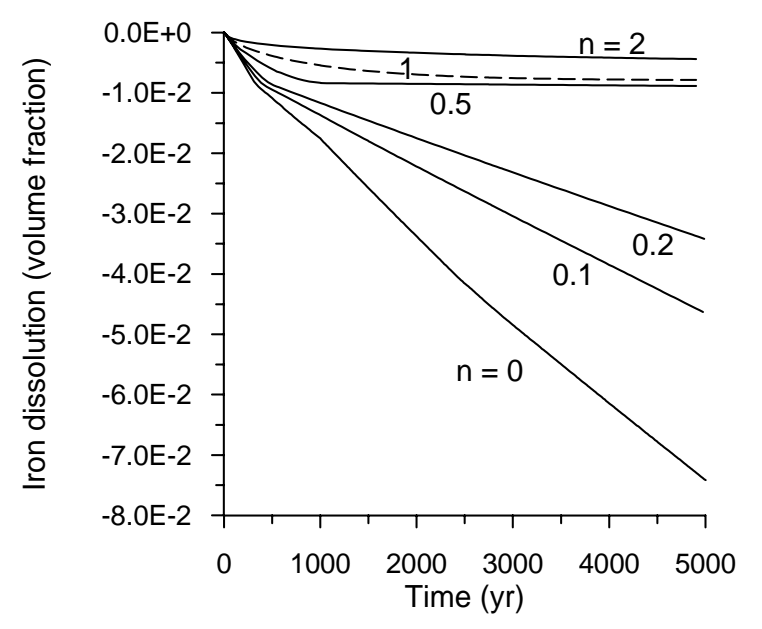

(a) Lower rate

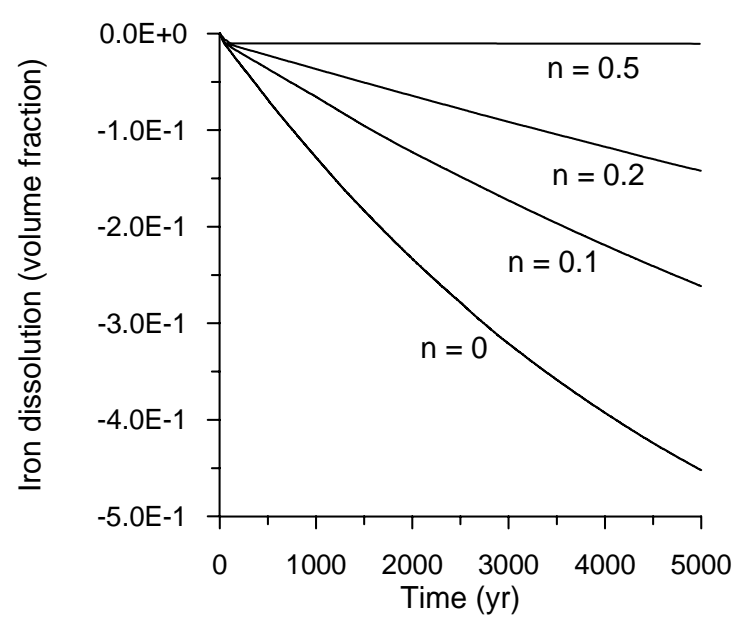

(b) Higher rate

Fig. 7. Iron dissolution (volume fraction in terms of medium accounting for a porosity of 0.1 over time at the canister for different $n$ values.

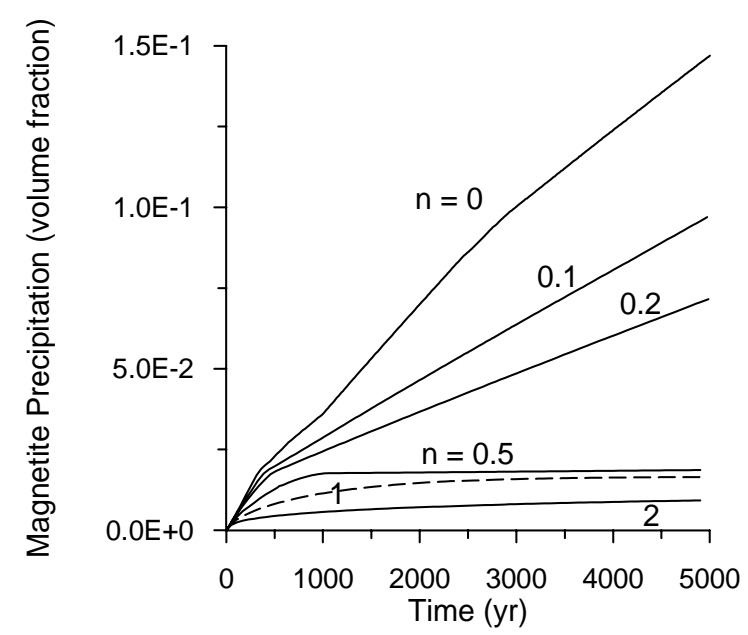

(a) Lower rate

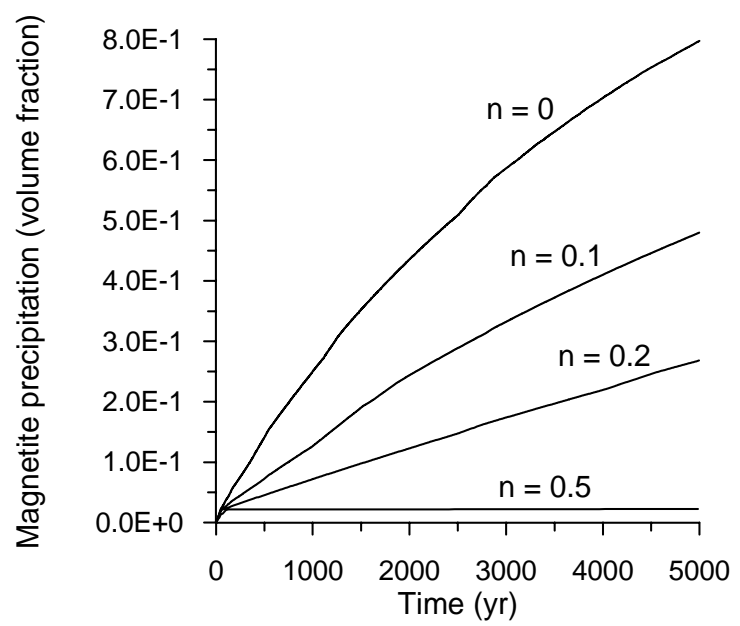

(b) Higher rate

Fig. 8. Magnetite precipitation (volume fraction in terms of medium) over time at the canister for different $n$ values.

As mentioned above, for the higher-rate base-case simulation gas pressure initially increases to a peak pressure of 100 bar after 1,000 years and then decreases gradually, because the iron volume fraction decreases significantly for this case. To see the long-term pressure evolution, simulations for both cases were performed for a much 
longer period. For the lower-rate base case, the iron is completely dissolved after about 150,000 years (Fig. 9a), and then no more $\mathrm{H}_{2}$ is generated, resulting in the pressure to recover close to the background level after about 200,000 years (Fig. 10a). For the higher-rate base case, iron disappears after about 23,000 years (Fig. 9b), which is much shorter than the lower-rate base case, and the pressure needs about 35,000 years to recover to background conditions (Fig. 10b).

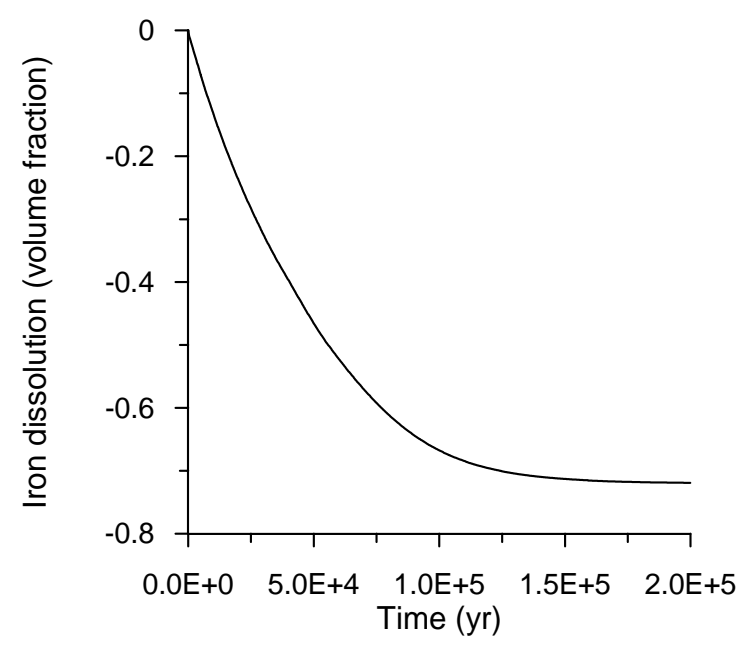

(a) Lower rate

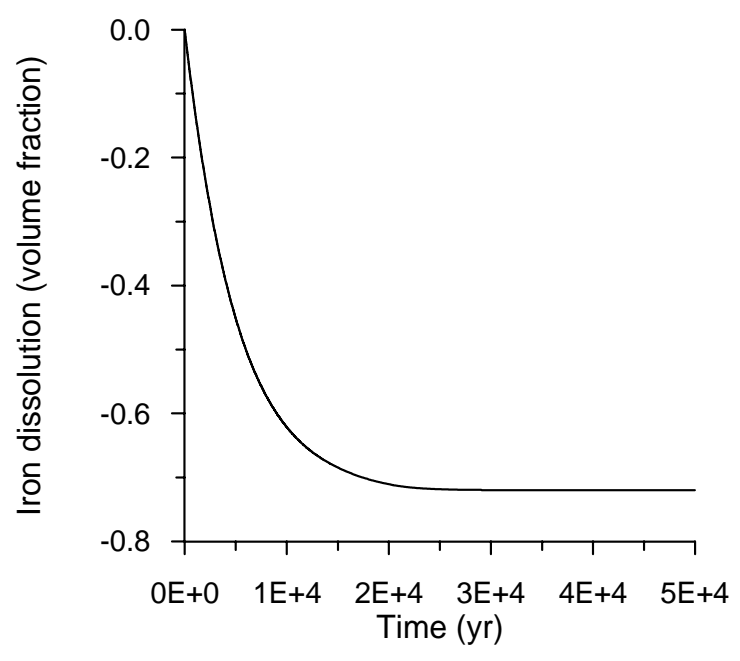

(b) Higher rate

Fig. 9. Iron dissolution (in volume fraction in terms of medium) over time at the canister surface for the base-case long-term simulations. (A maximum volume fraction of iron dissolution is 0.72 , which is in terms of medium accounting for a porosity of 0.1 . If in terms of the solid, the maximum iron dissolved is 0.8 as specified in the initial input) 


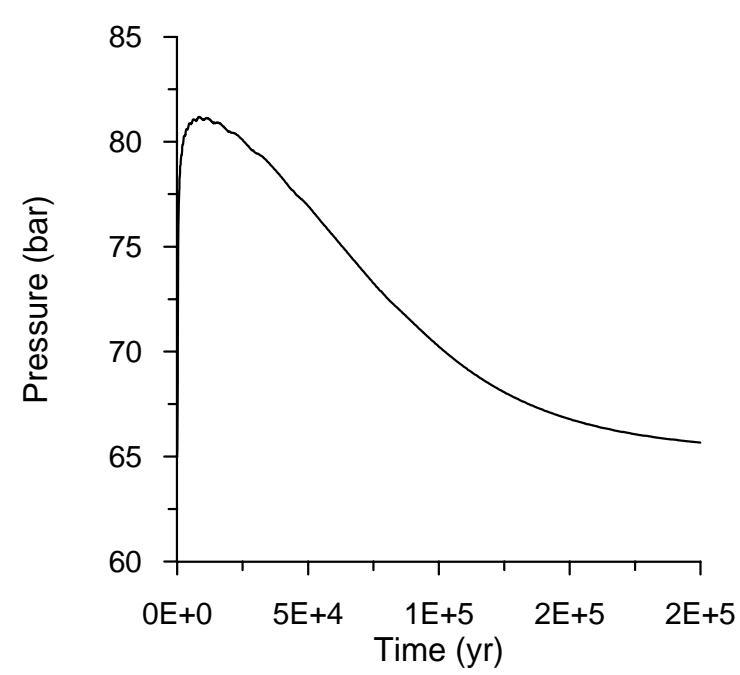

(a) Lower rate

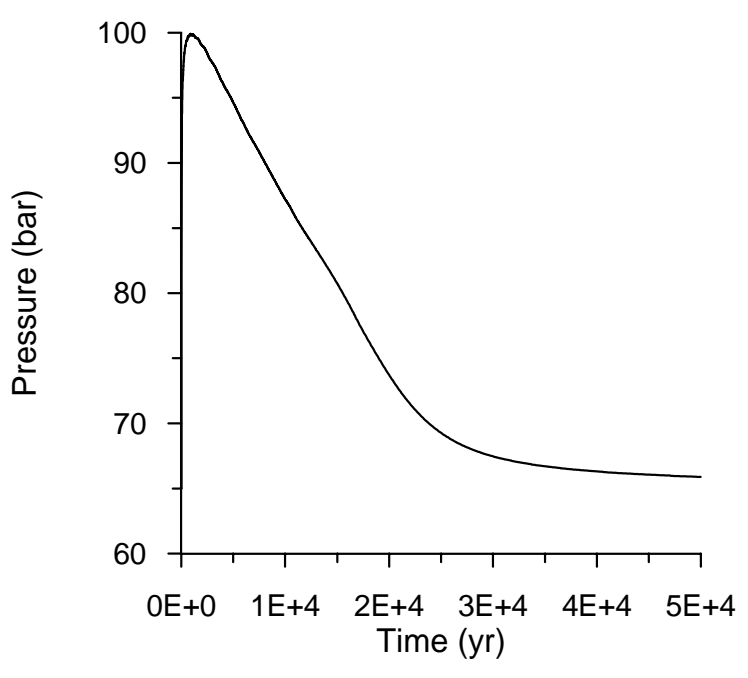

(b) Higher rate

Fig. 10. Pressure evolution over time at the canister for the base-case long-term simulations.

\section{Findings and Recommendations}

A chemistry model for simulating iron corrosion and the corresponding $\mathrm{H}_{2}$ generation and $\mathrm{H}_{2} \mathrm{O}$ consumption was implemented in a general-purpose reactive transport simulator, TOUGHREACT, which is coupled with a two-phase flow model to study $\mathrm{H}_{2}$ gas generation, pressure buildup, and saturation distribution in a nuclear waste repository. A number of simulations have been performed to evaluate key parameters and conditions on the $\mathrm{H}_{2}$ gas generation and associate pressure buildup in a generic HLW repository. Major findings and recommendations are given as follows:

For the lower corrosion rate constant $\left(2.0 \times 10^{-12} \mathrm{~mol} / \mathrm{m}^{2} / \mathrm{s}\right)$, if the rate does not depend on the water saturation (base-case), the pressure evolution profile is similar to the flow simulation that does not include the coupling with a chemistry model, reaching about 81 bars after 5,000 years. Iron volume decreases only slightly for this short time period, resulting in a near constant $\mathrm{H}_{2}$ generation rate. However, for long-term predictions, iron is completed converted to magnetite and $\mathrm{H}_{2}$ generation will decrease and 
stop after about 150,000 years. The pressure will recover to the background level after about 200,000 years.

For the higher- corrosion rate constant $\left(2.0 \times 10^{-11} \mathrm{~mol} / \mathrm{m}^{2} / \mathrm{s}\right)$, gas pressure initially increases to a peak pressure of 100 bar after 1,000 years followed by gradual decrease. The decrease in pressure is because the iron volume reduces significantly after about 5,000 years, causing a noticeable reduction in the $\mathrm{H}_{2}$ generation rate. Iron disappears after about 23,000 years, which is much shorter than that for the lower-rate base case, and the pressure recovers to the background pressure after only 35,000 years.

In our current model, the corrosion rate is linearly proportional to iron volume. This may be conservative, because a slight decrease in iron volume may result in a significant decrease in the corrosion rate due to possible coating of secondary minerals on the iron surface and blocking iron-water interaction. The base-case results for which the $\mathrm{H}_{2}$ generation rate only depends on the iron volume fraction provides an upper bound and a conservative estimate of pressure buildup, which is still lower than the results from the uncoupled flow simulation, particularly for the case with a high corrosion rate.

The results of the simulations considering corrosion rate as a function of water saturation indicates a gas pressure buildup significantly lower than that from the basecase simulations for which the corrosion rate is independent of water saturation. Determining the specific controls on the corrosion rate will be the topic of future sitespecific studies. As discussed above, laboratory data indicated that under atmospheric conditions the iron corrosion reaction rate did only decrease significantly if relative humidity decreases below 90\%. For the post-closure anaerobic conditions where temperature effects associated with radioactive decay have largely dissipated, the relative humidity at the canister surface remains relatively high (i.e., above 90\%), and the corrosion rate would remain high, even after the water saturation significantly decreases. Low humidity conditions, which can be expected during the early post-closure period characterized by aerobic conditions and heat generation from radioactive decay, will limit corrosion due to low water availability and small contact area. More complex interactions are associated with changes in the pore water chemistry and changes in the mineral composition in the buffer material. However, such phenomena can only be evaluated by applying the fully coupled two-phase geochemical model described above. 
The present modeling is for a generic clayey formation. However, this simplified modeling and the sensitivity analyses were useful in order to identify the role of some physical parameters on the $\mathrm{H}_{2}$ gas generation in a nuclear waste repository. The developed coupled model can be used in numerical experiments to describe the dynamic evolution of the system. Moreover, it provides a useful tool for gaining a better understanding of the coupled chemical and physical processes as well as controlling conditions and relevant parameters for $\mathrm{H}_{2}$ generation and migration.

Acknowledgment. We are grateful to Nicolas Spycher and Keni Zhang for a review of the manuscript and suggestions for improvement. We appreciate Eric Gaucher and the anonymous reviewer for their comments during the journal review process, which greatly improved the quality of the paper. This work was supported by the National Co-operative for the Disposal of Radioactive Waste (NAGRA) of Switzerland, and, in part, by the U.S. Dept. of Energy under Contract No. DE-AC02-05CH11231

\section{References}

Bauer, A., Berger, G., 1998. Kaolinite and smectite dissolution rate in high molar $\mathrm{KOH}$ solutions at $35^{\circ}$ and $80^{\circ} \mathrm{C}$. Applied Geochemistry, 13, 905-916.

Brown, P.W., Masters, L.W. 1982. Factors affecting the corrosion of metals in the atmosphere, Atmospheric Corrosion, Ed. W.H. Ailov, New York.

Bauer, A., Berger, G., 1998. Kaolinite and smectite dissolution rate in high molar $\mathrm{KOH}$ solutions at $35^{\circ}$ and $80^{\circ} \mathrm{C}$. Applied Geochemistry, 13, 905-916.

de Combarieu, G., Barboux, P., Minet, Y. 2007. Iron corrosion in Callovo-Oxfordian argilite: From experiments to thermodynamic/kinetic modeling. Physics and Chemistry of the Earth, 32, 346-358.

Davydov, A., Rybalka, K.V., Beketaeva, L.A., Engelhardt, G.R., Jayaweera, P., Macdonald, D.D., 2005. The kinetics of hydrogen evolution and oxygen reduction on Alloy 22. Corrosion Science, 47, 195-215.

Fernández, R., Cuevas, J., Sánchez, L., de la Villa, R.V., Leguey, S., 2006. Reactivity of the cement-bentonite interface with alkaline solutions using transport cells. Applied Geochemistry, 21, 977-992.

Finsterle, S., 1999. iTOUGH2 User's Guide, Report LBNL-40040, Lawrence National Berkeley Laboratory, Berkeley, California, USA.

Finsterle, S., 2004. Multiphase inverse modeling: Review and iTOUGH2 applications, Vadose Zone J., 3, 747-762. 
Galle, C., 2000. Gas breakthrough pressure in compacted Fo-Ca clay and interfacial gas overpressure in waste disposal context. Applied Clay Science, 17, 85-97.

Gaucher E.C., Blanc, P., Bardot, F., Braibant, G., Buschaert, S., Crouzet, C., Gautier, A., Girard, J.-P., Jacquot, E., Lassin, A., Negrel, G., Tournassat, C., Vinsot, A., Altmann, 2006. Modelling the porewater chemistry of the Callovian-Oxfordian formation at a regional scale. Comptes Rendus Geosciences 338(12-13), 917-930.

International Formulation Committee, 1967. A Formulation of the thermodynamic properties of ordinary water substance, IFC Secretariat, Düsseldorf, Germany.

Johnson, L.H., King, F. 2003. Canister Options for the Direct Disposal of Spent Fuel. NAGRA Technical Report NTB 02-11, NAGRA, Wettingen, Switzerland.

Lapuerta, S., Millard-Pinard, N., Moncoffre, N., Bérerd, N., Jaffrezic, H., Brunel, G., Crusset, D., Mennecart, T., 2007, Origin of the hydrogen involved in iron corrosion under irradiation, Surface and Coatings Technology, 201, 8197-8201.

Lasaga, A.C., Soler, J.M., Ganor, J., Burch, T.E., Nagy, K.L., 1994. Chemical weathering rate laws and global geochemical cycles. Geochimica et Cosmochimica Acta, 58, 2361-2386.

Mualem, Y., 1976, A new model for predicting the hydraulic conductivity of unsaturated porous media. Water Resour. Res. 12 6, 513 - 522.

NAGRA, 2002. Project Opalinus Clay: Safety Report. Demonstration of Disposal Feasibility (Entsorgungsnachweis) for Spent Fuel, Vitrified High-Level Waste and Long-Lived Intermediate-Level Waste, NAGRA Technical Report NTB 02-05, NAGRA, Wettingen, Switzerland.

NAGRA, 2004, Effects of Post-Disposal Gas Generation in a Repository for Spent Fuel, High-Level Waste and Long-Lived Intermediate Level Waste Sited in Opalinus Clay, NAGRA Technical Report NTB 04-06. NAGRA, Wettingen, Switzerland.

Narasimhan, T.N., Witherspoon, P.A., 1976. An integrated finite difference method for analyzing fluid flow in porous media, Water Resour. Res. 12, 57-64.

Neretnieks, I., 1985. Some Aspects of the Use of Iron Canisters in Deep Lying Repositories for Nuclear Waste, NAGRA Technical Report NTB 85-35, NAGRA, Wettingen, Switzerland.

Ortiz, L., Volckaert, G., Mallants, D., 2002. Gas generation and migration in Boom Clay, a potential host rock formation for nuclear waste storage. Engineering Geology, 64, 287-296.

Pearson, F.J., Arcos, D., Boisson, J.Y., Fernandez, A.M., Gäbler, H.E., Gaucher, E., Gautschi, A., Griffault, L., Hernan, P., Waber, H.N., 2003. Mont Terri project Geochemistry of water in the Opalinus clay formation at the Mont Terri Rock Laboratory. In Geology Series, Vol. 5 (ed. F.O.W.G.).

Philippini, V., Naveau, A., Catalette, H., Leclercq, S., 2006. Sorption of silicon on magnetite and other corrosion products of iron. Journal of Nuclear Materials, 348, 60-69. 
Pruess, K., 1991. TOUGH2: A General-Purpose Numerical Simulator for Multiphase Fluid and Heat Flow, Report LBL-29400, Lawrence Berkeley Laboratory, Berkeley, California, USA.

Reardon, E. J., 1995. Anaerobic corrosion of granular iron: Measurement and interpretation of hydrogen evolution rates. Environ. Sci. Technol., 29, 2936-2945.

Reardon, E., 2005. Zerovalent irons: Styles of corrosion and inorganic control on hydrogen pressure buildup. Environmental Science \& Technology, 39, 7311-7317.

Senger, R., Marschall, P.M.., Finsterle, S., 2007. Investigation of Two-Phase Flow Phenomena Associated with Corrosion in an SF/HLW Repository in Opalinus Clay, Switzerland, in Clays in Natural \& Engineered Barriers for Radioactive Waste Confinement, 3rd International Meeting, Lille, September 17 - 20, 2007.

Van Genuchten, M. Th., 1980. A Closed-form equation for predicting the hydraulic conductivity of unsaturated soils. Soil Sci. Soc. Am. J. 44, $892-898$.

Wolery, T.J., 1992. EQ3/6: Software Package for Geochemical Modeling of Aqueous Systems: Package Overview and Installation Guide (Version 7.0), Report UCRL-MA110662 PT I, Lawrence Livermore National Laboratory, Livermore, California, USA.

$\mathrm{Xu}, \mathrm{T}$., Pruess, K., 2001. Modeling multiphase non-isothermal fluid flow and reactive geochemical transport in variably saturated fractured rocks: 1. Methodology, American Journal of Science, 301, 16-33.

Xu, T., Sonnenthal, E.L., Spycher, N., Pruess, K., 2006. TOUGHREACT: A simulation program for non-isothermal multiphase reactive geochemical transport in variably saturated geologic media, Computer \& Geoscience, 32, 145-165. 